\title{
Research on the Impact of Ecological Civilization Construction on Environmental Pollution Control in China-Based on Differential Game Theory
}

\author{
Liuwei Zhao' ${ }^{1}$ and Shuai Jin $\mathbb{D D}^{2}$ \\ ${ }^{1}$ School of Business, Jiangsu University of Technology, Changzhou, Jiangsu 213001, China \\ ${ }^{2}$ Computational Experiment Center for Social Science, School of Management, Jiangsu University, \\ Zhenjiang, Jiangsu 212013, China
}

Correspondence should be addressed to Shuai Jin; sjin@ujs.edu.cn

Received 11 January 2021; Revised 17 February 2021; Accepted 25 February 2021; Published 4 March 2021

Academic Editor: Stefania Tomasiello

Copyright (C) 2021 Liuwei Zhao and Shuai Jin. This is an open access article distributed under the Creative Commons Attribution License, which permits unrestricted use, distribution, and reproduction in any medium, provided the original work is properly cited.

\begin{abstract}
With environmental pollution problems becoming more and more serious, administrators need to change their original system of performance achievement evaluation and build a new performance achievement view of ecological civilization. Based on the view of achievement evaluation of ecological civilization, this research develops a continuous-time differential game of environmental pollution control between local government and enterprises by taking into consideration dynamic change in pollutants in the environment into account. By analyzing the equilibrium solution of the game, the role of the assessment mechanism of ecological civilization is explored, and countermeasures are proposed to provide a scientific basis for improving the assessment mechanism of ecological civilization in China's environmental pollution control. The results have shown that enterprises' equilibrium pollutants output is negatively correlated to Ecological Civilization Index. Instead, the government's efforts to curb pollutions are positively correlated to the environmental review. With th 'at, lowering enterprises' cost of production and pollution reduction alongside imposing more severe punishment would help improve pollution management. Setting up reasonable reward-punishment system would improve local governments' pollution management. Elsewhere, the research employs the method of numerical simulation to testify the relationship among the importance of environmental review, enterprises' pollutant output, and government's efforts to manage pollutions. Finally, the research also suggests necessary measures to solve environmental pollutions and introduces a numerical simulation analysis.
\end{abstract}

\section{Introduction}

When the environment increasingly experienced heavier environmental burden, and pollutions caused by social and economic activities have become gradually unbearable, environmental problems will become the bottleneck for the development of each country [1-3]. The contradiction between limited natural resources and the growth of human demand is one of the core issues of regional and global sustainable development [4]. The Chinese economy has prospered for over 40 years, creating a miracle of robust economic growth, but the problem of environmental pollution has worsened. The problem of environmental pollution has become an important constraint factor, hindering people's aim to improve quality of living standards. Improving environmental quality has undoubtedly played a key role in improving people's standards of living [5].

In order to improve the ecological environment, China began to launch a national-level strategy for the first time since the $10^{\text {th }}$ Five-Year Plan. "Sustainable development strategy" proposed from the $15^{\text {th }}$ National Congress of the Communist Party of China to the $19^{\text {th }}$ National Congress of the CPC emphasized that "Lucid waters and lush mountains are invaluable assets." Environmental protection strategies are playing an increasingly important role in government management and social governance in China. Therefore, as 
an important policy tool, the assessment of ecological civilization has become an important means to solve ecological environment problems and coordinate the relationship between environmental protection and economic development (ecological civilization is a new stage for civil development. That is to say, the civilization after the industrial revolution is a sum of material and spiritual civilization caused by harmony among humans, nature, and society. The harmony among nature, humans, and society, which would achieve sustainable development and virtuous cycle, should be an ideal way of living. Based on the perspective of harmony between humans and nature as well as the viewpoint of the $18^{\text {th }}$ National Congress of the Communist Party of China, ecological civilization is the sum of materials, spirits, and institutions after human beings successfully protected and created ideal ecological environments. The impressive results would come from successful engineering systems of economic, political, cultural, and social construction. The results are also the measures of civilization development).

Political performance review is an important tool to help advance the modernization of the country's governance system and capacity for governance. In China's environmental governance, most scholars believe that the central government's long-term implementation of "GDP-only" performance evaluations of local officials has led to a lack of fundamental institutional incentives for environmental governance [6]. Some related issues have been discussed in existing research; for example, using the principal-agent framework, Liu et al. pointed out that the binding targets of the "eleventh five-year plan" clearly defined the administrative responsibilities of local governments and the consequences of rewards and punishments in environmental governance, and the political pressure brought by the assessment on local officials improved the intensity and effectiveness of policy implementation. However, in the process of evaluation, problems such as distorted evaluation results failure of evaluation incentives and loss of control over evaluation constraints have emerged due to asymmetric information. Most of these studies are limited to the theoretical level, and there is not much literature on the quantitative assessment of environmental performance from the perspective of game theory $[7,8]$.

At present, many scholars have applied the game theory method to studying the environmental pollution control problem. In real economic activities, due to the influence of the external environment, information, cognitive constraints, and other factors, rational decision-making is difficult [9]. Based on the perspective of the circular industrial chain, the stakeholders of enterprises, governments, and consumers in the resource treatment of livestock and poultry wastes are incorporated into an evolutionary game system to explore the interaction results between network cooperation subjects in the circular economy [10]. Analyzing the relationship between related stakeholders in environmental governance is essential for the model [11]. In environmental governance, enterprises are the source of environmental pollution and the main body of governance, while the government is the main body of environmental standard formulation and supervision. Therefore, there are many evolutionary game studies with the government and enterprises as the game players. By constructing the game model of government and enterprise and interenterprise and intergovernment evolution, we will study the influencing factors of local government's environmental regulation strategy [12], the influence of carbon tax and subsidy on manufacturers' low-carbon strategy choice [13], the strategic choice behavior of enterprises and environmental protection departments, and causes of enterprise pollution, prevention, and control focus [14]. Benhong et al. establish an evolutionary game model between government regulatory departments and electronic and electrical products' manufacturing enterprises and to carry out simulation analysis under different strategies [15]. Benhong et al. studied from the perspective of enterprises that the establishment of a cooperative mechanism for resource sharing in the ecosystem can effectively promote value cocreation, thereby improving the environmental performance of enterprises [16].

Now, the use of differential game method to discuss environmental pollution control is at the initial stage. Yeung established a cooperative differential game model for crossborder industrial pollution. The main characteristics of the model are as follows: various industrial enterprises are competing with each other, and the governments cooperate with each other in the treatment of environmental pollution, and for the first time, they obtain a time-consistent solution in the cooperative differential game of pollution control, and for the first time, a time-consistent solution was obtained in the cooperative differential game of pollution control [17]. Kossioris and Plexousakis pointed out that the dynamic problems of pollution and resource management need to be analyzed with the framework of differential game, and the nonlinear feedback Nash equilibrium solution of lake pollution control is obtained [18]. Finally, the feedback Nash equilibrium solutions, optimal control solutions, and openloop Nash equilibrium solutions are compared. Yeung used the method of differential countermeasures to explore the game between policymakers and enterprises that pursued maximum profits while causing pollution. In this game, the government decided the level of pollution tax collection, and the enterprise determined the output level, obtained feedback Nash equilibrium solution, and extended the game to multiple enterprises. Akihiko Yanase established a differential game model for international pollution control [19]. The study points out that the level of environmental policy determined deviates from the social optimal level in the noncooperative policy game, and the equilibrium result of emission tax game is worse than that of command-control game. This is because the emission tax will cause more pollution and a decline in social welfare.

Due to the special attributes of environmental indicators, the academic literature on environmental performance appraisal focuses on the following three aspects: first, the analysis and research on the practice and exploration of environmental performance appraisal; second, the establishment of environmental performance appraisal indicator system, including the principles of index construction, the selection and design of indicators, and the determination of 
weights; and third, the government's environmental performance appraisal system research, including the determination of the object of assessment, the standard of assessment criteria, and the selection of assessment methods. However, most of these studies are limited to the theoretical level, and there is not much literature on the quantitative assessment of environmental performance from the perspective of game theory.

Environmental pollution control is a continuous dynamic game process. Differential game is a dynamic game model that studies the competition and cooperation of two or more parties in a continuous tablet. Therefore, based on the differential game model, this paper constructs a game model of environmental pollution control between the government and enterprises under the constraint of the evaluation mechanism of ecological civilization. The following issues are studied:

First, how does the introduction of the assessment mechanism of ecological civilization construction interfere with the dynamic evolution of the pollutant stock?

Second, how does this dynamic alter the efficient setting of the punishment level for a given level of emissions?

Third, what strategies would come out when the central and local information is asymmetric in the evaluation of ecological governance performance of local government?

This paper is organized as follows. In Section 2, we construct a continuous-time differential game of environmental pollution control between local government and enterprises by taking into consideration dynamic change in pollutants in the environment into account. Impact analysis of feedback Nash equilibrium of the system is discussed in Section 3. In Section 4, a numerical illustration serves to illustrate (i) how dynamic state variables shape expectations and variance in the stock of pollutants and (ii) how related and key parameter values affect equilibrium strategies of both sides of the game. In Section 5, the policy recommendations for this study are given. Finally, the conclusions and limitations of this study are given.

\section{Methodology}

2.1. Problem Characteristics and Basic Assumptions. Due to the existence of conflicts of interest in economic development and environmental protection, enterprises environmental pollution control has typical game characteristics, which also makes game theory one of the important tools for studying ecological environmental governance [20, 21]. For the convenience of research, it is assumed that, within a continuous-time $s \subset\left[t_{0}, t\right]$, there is a superior government supervision department, a local government supervision department, and $n$ polluting enterprises in a certain area. $n$ polluting enterprises will carry out a certain amount of sewage in any time $s$, which will have a direct impact on the dynamic system of the ecological environment. The pollution of the ecological environment will cause damage to enterprises and the government. The damage cost is a linear function of the level of pollutants in the ecological environment. It is assumed that the polluting enterprises are "economic man" with limited rationality. In order to pursue the maximum profit, it will risk the selection of environmental violations such as discharge pollutant without permission, beyond pollution limits, and other illegal activities. If $q_{i}(s)$ represents the output level of enterprise $i$ within time $s$, the yield of $q_{i}(s)$ will also produce $e_{i}(s)=\gamma q_{i}(s)(\gamma>0)$ pollutants. The polluting enterprise obtains income through production and operation, and the amount of pollutants is related to the output of its production. Therefore, the polluting enterprise's production gain and production cost can be written as a function of pollutant $e_{i}(s)$. Under the supervision of the government, polluting enterprises $i$ will take measures to control the generated pollutants, and its cost function $C_{i}$ is a concave function, namely, $C_{i}^{\prime \prime}>0$. Similarly, the government will also deal with environmental pollution, and its cost function $C_{g}$ is also a concave function, namely, $C_{g}^{\prime \prime}>0$. The superior government will give certain rewards and punishments according to the local government's ecological civilization and environmental protection performance. The size of the rewards and punishments is a linear function of the ecological civilization and environmental performance. Finally, it is assumed that the government and the polluting enterprises have the same discount rate $\rho$.

2.2. Environmental Quality Dynamic Equation. The environmental quality dynamic equation $[22,23]$ is as follows:

$$
\begin{aligned}
\dot{E}(s) & \left.=m\left(P_{\max }-E(s)\right)+\sum_{j=1}^{n}\left[e_{j}(s)-\operatorname{Re}_{j}(s)\right)\right]-\beta \mu(s), \\
E\left(s_{0}\right) & =E_{0}=200
\end{aligned}
$$

where $E(s)$ represents the amount of pollutants in the ecosystem. Dynamic changes in environmental quality $\dot{E}(s)$ mainly depends on three variables: the total amount of pollutants discharged by $n$ polluting enterprises, the amount of pollutants that local governments have eliminated through pollution control, and the amount of pollutants that the ecosystem system absorbs through its self-circulation. $e_{j}(s)$ represents the amount of pollution generated by the polluting enterprises $j$ during the production and the operation process, but not necessarily all of them are discharged into the environment; $R_{j}(0<R<1)$ represents the purification rate of pollutants generated during the production and the operation process by the enterprise $j$ 's technological innovation; $R_{j} e_{j}(s)$ represents the amount of pollutants purified by the enterprise's technological innovation; $\left.\sum_{j=1}^{n}\left[e_{j}(s)-\operatorname{Re}_{j}(s)\right)\right]$ indicates the total amount of pollutants discharged by the polluting enterprises $n ; \beta \mu(s)$ indicates the elimination of the amount of pollutants in the eco-environment system through local government efforts; $\beta(\beta>0)$ indicates the rate of pollutants eliminated by local governments in the fight against pollution; $m E(s)$ is the pollution flow absorbed by the ecological environment 
system during the self-circulation process; and $m$ indicates the self-purification rate of the ecological environment system. It is assumed here that the self-absorption capacity of the ecological environment system is a decreasing function of the pollution stock. That is to say, the heavier the pollution is, the worse the environmental self-purification ability could be; $P_{\max }$ indicates that there is a maximum level of pollution, and $P_{0}$ represents the initial level of pollutants in the eco-environment system at time $t_{0}$.

2.3. Enterprise Objective Function. The objective function of the enterprise is as follows:

$$
\int_{t_{0}}^{t}\left\{\begin{array}{l}
a_{i} e_{i}(s)-\frac{v_{i}}{2}\left(e_{i}(s)\right)^{2}+k\left[e_{i}(s)-R_{i} e_{i}(s)-\bar{e}_{i}\right]-\frac{C_{i}}{2}\left(R_{i} e_{i}(s)\right)^{2} \\
-b E(s)-G\left(e_{i}(s)-R_{i} e_{i}(s)\right)-\alpha(s) g\left[e_{i}(s)-R_{i} e_{i}(s)-\bar{e}_{i}\right] \omega
\end{array}\right\} e^{-\rho\left(s-t_{0}\right)} \mathrm{d} s .
$$

The income of the enterprise can be divided into two parts: one is the net income brought by the production and operation of the enterprise, and the other part is the income from the excessive discharge of the enterprise. The net income of the enterprise is the production utility minus the production cost. According to the hypothetical net income, it is related to $e_{i}(s)$, which is $a_{i} e_{i}(s)-\left(v_{i}\left(e_{i}(s)\right)^{2} / 2\right)$, where $a_{i}$ and $v_{i}$ represent the utility and cost coefficients, respectively, and $a_{i}>0, v_{i}>0 . k\left[e_{i}(s)-R_{i} e_{i}(s)-\bar{e}_{i}\right]$ indicates the additional benefits that the excess pollutants bring to the enterprise $i$, where $\bar{e}_{i}$ is the maximum amount of pollutants that the environmental protection department permits and $k(k>0)$ indicates the coefficient of return that the unit exceeds the standard amount of pollutants.

The cost and expenses of the enterprise include the following: the damage cost to the enterprise caused by environmental pollution $b E(s)(b>0)$, the sewage charges paid by the enterprise, the cost of abatement, and the fines paid after the company exceeds the standard discharge. The cost and expenses of the enterprise include the following: the damage cost to the enterprise caused by environmental pollution, the emission charges paid by the enterprise, the cost of emission reduction, and the fines paid after the enterprise exceeds the standard discharge. According to Article 12 of the Regulations on the Administration of the Collection and Use of Emission Charges, which was implemented by the People's Republic of China in 2003, pollutants discharged into the environment shall be paid in a quantity according to the amount and $G$ shall be recorded as the cost of unit discharge; $G\left(e_{i}(s)-R_{i} e_{i}(s)\right)$ indicates the emission charges paid by the enterprise $i$ to the local government. $\left(\left(R_{i} e_{i}(s)\right)^{2} C_{i}\right) / 2\left(C_{i}>0\right)$ is the cost of pollution control required by the enterprise $i$ to reduce the amount of $R_{i} e_{i}(s)$ pollutants. $\alpha(s) g\left[e_{i}(s)-R_{i} e_{i}(s)-\bar{e}_{i}\right] \omega$ indicates the amount of fines paid by the enterprise $i$ after the government found out that the pollutants were discharged; $\alpha(s) g$ indicates the possibility of the enterprise's excessive discharge of pollutants, where $g$ is the level of government's ecological civilization and environmental performance and $\alpha(s)$ is the importance of ecological civilization and environmental performance assessment (the higher the importance, the more the local government pays more attention to the environment, and the stronger the supervision) calculates the fine to be paid by the company exceeding the standard of pollutant discharge. $\omega$ represents the unit penalty to be paid by the enterprise whose exceeds the standard of pollutant discharge quantity.

2.4. Government Objective Function. The objective function of the government is as follows:

$$
\int_{t_{0}}^{t}\left\{\begin{array}{c}
\sum_{j=1}^{n}\left[a_{j} e_{i j}(s)-\frac{v_{j}}{2}\left(e_{j}(s)\right)^{2}\right]+\sum_{j=1}^{n} \mathrm{G}\left(e_{j}(s)-\operatorname{Re}_{j}(s)\right)-\frac{C_{g}}{2}(\beta \mu(s))^{2} \\
+\sum_{j=1}^{n} \alpha(s) g\left[e_{j}(s)-\operatorname{Re}_{j}(s)-\bar{e}_{j}\right] \omega+\frac{\vartheta \alpha(s)}{2}\left[g \mu(s)-g_{0} \mu_{0}(s)\right]-\zeta E(s)
\end{array}\right\} e^{-\rho\left(s-t_{0}\right) \mathrm{d} s .}
$$

The government's income mainly consists of four parts: the material welfare created by the enterprise production and operation for the society, the pollutant discharge paid by the enterprise, the fines paid after the enterprise exceeds the standard pollutant discharge, and the rewards given by the superior government. The government's losses and costs are composed of three parts: $\beta \mu(s)(\beta>0)$ is the damage to the local people caused by environmental pollution, the other is the governance cost that the government spends to manage the environment $C_{g}(\beta \mu(s))^{2} / 2\left(C_{g}>0\right)$, and the third part is the punishment given by the unqualified of the superior government. 
$\sum_{j=1}^{n}\left[a_{j} e_{i j}(s)-v_{j}\left(e_{j}(s)\right)^{2} / 2\right]$ indicates the material welfare created by the enterprise's production and operation for the society, and it is also the GDP growth part created for the country; $\sum_{j=1}^{n} G\left(e_{j}(s)-\operatorname{Re}_{j}(s)\right)$ represents the income from the enterprises' pollutant charges to the government; $\vartheta \alpha(s)\left[g \mu(s)-g_{0} \mu_{0}(s)\right] / 2 \quad(\vartheta>0)$ represents the superior government rewards and punishments for local governments, where $g_{0}$ and $\mu_{0}(s)$ represent the standard values of ecological civilization achievements and environmental governance efforts formulated by the superior government to local governments, respectively. When the product of local government's environmental governance efforts and ecological civilization construction $g \mu(s)$ is greater than the critical value $g_{0} \mu_{0}(s), \vartheta \alpha(s)\left[g \mu(s)-g_{0} \mu_{0}(s)\right] / 2$ represents the reward given by the superior government to the local government; on the contrary, when the product of local government's environmental governance efforts and ecological civilization construction $g \mu(s)$ is less than the critical value $g_{0} \mu_{0}(s), \quad \vartheta \alpha(s)\left[g \mu(s)-g_{0} \mu_{0}(s)\right] / 2$ represents the punishment given by the superior government to the local government.

2.5. Model Solution. In order to make equation (1) have a unique continuous solution $E(s)$, first, we need to construct a set of bounded, continuous, and differentiable value functions $V_{c}(E)$ and $V_{g}(E)$. Therefore, the Hamilton-Jacobi-Bellman (HJB) equation is constructed as follows:

$$
\begin{aligned}
& \rho V_{c}(E)=\operatorname{Max}_{e_{i}(s) \geq 0}\left\{\begin{array}{c}
a_{i} e_{i}(s)-\frac{v_{i}}{2}\left(e_{i}(s)\right)^{2}+k_{i}\left[e_{i}(s)-\operatorname{Re}_{i}(s)-\bar{e}_{i}\right]-G\left(e_{i}(s)-\operatorname{Re}_{i}(s)\right) \\
-b E(s)-\frac{C_{i}}{2}\left(\operatorname{Re}_{i}(s)\right)^{2}-\alpha(s) g\left[e_{i}(s)-\operatorname{Re}_{i}(s)-\bar{e}_{i}\right] \omega
\end{array}\right\} \\
& +V_{c}^{\prime}(E)\left\{\begin{array}{c}
m\left(P_{\max }-E(s)\right)-\beta \mu(s) \\
\left.+\sum_{j=1}^{n}\left[e_{j}(s)-\operatorname{Re}_{j}(s)\right)\right]
\end{array}\right\}, \\
& \rho V_{g}(E)=\operatorname{Max}_{e_{i}(s) \geq 0}\left\{\begin{array}{c}
\sum_{j=1}^{n}\left[a_{j} e_{i j}(s)-\frac{v_{j}}{2}\left(e_{j}(s)\right)^{2}\right]+\sum_{j=1}^{n} \alpha(s) g\left[e_{j}(s)-\operatorname{Re}_{j}(s)-\bar{e}_{j}\right] \omega-\zeta E(s) \\
+\sum_{j=1}^{n} G\left(e_{j}(s)-\operatorname{Re}_{j}(s)\right)+\frac{\vartheta \alpha(s)}{2}\left[g \mu(s)-g_{0} \mu_{0}(s)\right]-\frac{C_{g}}{2}(\beta \mu(s))^{2}
\end{array}\right\} \\
& +V_{g}^{\prime}(E)\left\{\begin{array}{c}
m\left(P_{\max }-E(s)\right)-\beta \mu(s) \\
\left.+\sum_{j=1}^{n}\left[e_{j}(s)-\operatorname{Re}_{j}(s)\right)\right]
\end{array}\right\} .
\end{aligned}
$$

First, equation (4) finds the first-order partial derivative with respect to $e_{i}(s)$ and obtains the following equation:

$$
\begin{gathered}
a_{i}-v_{i} e_{i}(s)+k_{i}(1-R)-G(1-R)-C_{i} \operatorname{Re}_{i}(s) \\
-\omega \alpha(s) g(1-R)+V_{c}^{\prime}(E)(1-R) n=0 .
\end{gathered}
$$

After simplification, we can get the following equation:

$$
e_{i}(s)=\frac{a_{i}+\left(k_{i}-G-\omega \alpha(s) g+V_{c}^{\prime}(E) n\right)(1-R)}{v_{i}+C_{i} R^{2}} .
$$

Next, equation (5) finds the first-order partial derivative with respect to $\mu(s)$. After simplification, we can get the following equation:

$$
\mu(s)=\frac{g 9 \alpha(s)-2 \beta V_{g}^{\prime}(E)}{2 C_{g} \beta^{2}} .
$$

In order to obtain a linear value function, let $V_{c}(E)=$ $l_{1}+h_{1} E(s)$ and $V_{g}(E)=l_{2}+h_{2} E(s)$, where $l_{1}, l_{2}, h_{1}$, and $h_{2}$ are all constants. Then, substituting $V_{c}^{\prime}(E)=h_{1}, V_{g}^{\prime}(E)=h_{2}$ 
into equations (4) and (5), the following equation is obtained:

$$
\begin{aligned}
\rho\left(l_{1}+h_{1} E(s)\right)= & a_{i} e_{i}(s)-\frac{v_{i}}{2}\left(e_{i}(s)\right)^{2}+k_{i}\left[e_{i}(s)-\operatorname{Re}_{i}(s)-\bar{e}_{i}\right]-b E(s)-G\left(e_{i}(s)-\operatorname{Re}_{i}(s)\right)-\frac{C_{i}}{2}\left(\operatorname{Re}_{i}(s)\right)^{2} \\
& \left.-\alpha(s) g\left[e_{i}(s)-\operatorname{Re}_{i}(s)-\bar{e}_{i}\right] \omega+h_{1}\left\{m\left(P_{\max }-E(s)\right)+\sum_{j=1}^{n}\left[e_{j}(s)-\operatorname{Re}_{j}(s)\right)\right]-\beta \mu(s)\right\} . \\
\rho\left(l_{2}+h_{2} E(s)\right)= & \sum_{j=1}^{n}\left[a_{i} e_{i}(s)-\frac{v_{i}}{2}\left(e_{i}(s)\right)^{2}\right]+\sum_{j=1}^{n}\left[\operatorname{Ge}_{j}(s)-\operatorname{Re}_{j}(s)\right]-\frac{C_{g}}{2}(\beta \mu(s))^{2}+\sum_{j=1}^{n} \alpha(s) g\left[e_{j}(s)-\operatorname{Re}_{j}(s)-\bar{e}_{j}\right] \omega \\
& \left.+\frac{\vartheta \mu(s)}{2}\left[g \mu(s)-g_{0} \mu_{0}(s)\right]-\zeta E(s)+h_{2}\left\{m\left(P_{\max }-E(s)\right)+\sum_{j=1}^{n}\left[e_{j}(s)-\operatorname{Re}_{j}(s)\right)\right]-\beta \mu(s)\right\} .
\end{aligned}
$$

From equation (9), we can know that the following equation is established:

$$
\rho h_{1} E(s)=-b E(s)-h_{1} m E(s) .
$$

By simplification of equation (11), the following equation can be obtained:

$$
h_{1}=\frac{-b}{\rho+m} \text {. }
$$

Similarly, we can get

$$
\begin{aligned}
\rho h_{2} E(s) & =-\zeta E(s)-h_{2} m E(s), \\
h_{2} & =\frac{-\zeta}{\rho+m} .
\end{aligned}
$$

As a result, we get

$$
\begin{aligned}
& V_{c}^{\prime}(E)=h_{1}=\frac{-b}{\rho+m}, \\
& V_{g}^{\prime}(E)=h_{2}=\frac{-\zeta}{\rho+m} .
\end{aligned}
$$

Substituting equations (14) and (15) into (7) and (8), the simplification can be obtained as a feedback Nash equilibrium strategy $\left[e_{i}^{*}(s), \mu^{*}(s)\right]$ in the following form:

$$
\begin{aligned}
e_{i}^{*}(s) & =\frac{a_{i}(\rho+m)+(1-R)((\rho+m)(k-G-\omega \alpha(s) g)-b n)}{\left(v_{i}+C_{i} R^{2}\right)(\rho+m)}, \\
\mu^{*}(s) & =\frac{g \vartheta \alpha(s)(\rho+m)+2 \zeta \beta}{2(\rho+m) C_{g} \beta^{2}}
\end{aligned}
$$

\section{Impact Analysis of Feedback Nash Equilibrium}

(1) The equilibrium pollutant production of enterprises $e_{i}^{*}(s)$ is negatively correlated with the importance of ecological civilized environmental performance assessment $\alpha(s)$, and equation (16) finds the first-order partial derivative with respect to $\alpha(s)$; we can get descent gradient $\left(\omega g(1-R) /\left(v_{i}+C_{i} R^{2}\right)\right)$. By partial guidance of the equilibrium pollutant production $e_{i}^{*}(s)$ on the importance of the assessment of ecological civilization and environmental performance $\alpha(s)$, we can obtain $\left(\partial e_{i}^{*}(s) / \partial \alpha(s)\right)=(-\omega g$ $\left.(1-R) /\left(v_{i}+C_{i} R^{2}\right)\right)$. Since $0<R<1$ and $\omega, g, v_{i}$, and $C_{i}$ are all greater than zero, $(-\omega g(1-R)$ $\left./\left(v_{i}+C_{i} R^{2}\right)\right)<0$ is always established. Therefore, it can be explained that the equilibrium pollutant production of the enterprise $e_{i}^{*}(s)$ is negatively correlated with the importance of the ecological civilization and environmental performance assessment $\alpha(s)$. The descent gradient is $(\omega g(1-R)$ $\left./\left(v_{i}+C_{i} R^{2}\right)\right)$; that is, when the superior government raises the importance of assessing the ecological civilization and environmental protection performance, and the local government will pay more attention to environmental protection performance. On the one hand, the local governments will take more effective measures to control the discharge of pollutants; on the other hand, the supervision of the pollutant enterprises will continue to strengthen, which will help curb enterprise discharge pollutant without permission, beyond pollution limits, and other illegal activities.

(2) The government's equilibrium environmental governance efforts $\mu^{*}(s)$ are positively related to the 
importance of ecological civilization and environmental performance assessment $\alpha(s)$, and equation (17) finds the first-order partial derivative with respect to $\alpha(s)$; we can get ascent gradient $\left(g 9 / 2 C_{g} \beta^{2}\right)$. By partial guidance of the equilibrium environmental governance efforts $\mu^{*}(s)$ on the importance of the assessment of ecological civilization and environmental performance $\quad \alpha(s)$, we can obtain $\left(\partial \mu^{*}(s) / \partial \alpha(s)\right)=\left(g \vartheta / 2 C_{g} \beta^{2}\right)$. Since $g, \vartheta, C_{g}$, and $\beta$ are all greater than zero, then $\left(g 9 / 2 C_{g} \beta^{2}\right)>0$ is always established. This shows that the government's equilibrium environmental governance efforts $\mu^{*}(s)$ are monotonously increasing function, and the importance of ecological civilization and environmental performance assessment will promote the government's equilibrium environmental governance efforts, so as to obtain better environmental pollution control effects.

(3) The equilibrium pollutant production of enterprise $e_{i}^{*}(s)$ is negatively correlated with the unit of pollutant charge $G$, and equation (16) finds the first-order partial derivative with respect to $G$; we can get descent gradient $\left(1-R /\left(v_{i}+C_{i} R^{2}\right)\right)$. With partial guidance of the equilibrium pollutant production $e_{i}^{*}(s)$ on the pollutant charge $G$, we can obtain $\left(\partial e_{i}^{*}(s) / \partial G\right)$ $=\left(-(1-R) /\left(v_{i}+C_{i} R^{2}\right)\right)$. Since $0<R<1$ and $v_{i}$ and $C_{i}$ are all greater than zero, then $\left(-(1-R) /\left(v_{i}\right.\right.$ $\left.\left.+C_{i} R^{2}\right)\right)<0$ is always established. Therefore, we can know that when the government raises the amount of the unit of pollutant charge, the production and operation cost of the enterprise will increase, and the enterprise will take measures to control the pollutant discharge, which can play a role in restraining the pollution output of the enterprise.

(4) The reduction in the production and operation costs and environmental treatment costs of enterprises can all improve the pollution control effect of ecological civilization and environmental performance assessment. The reduction in emissions costs of enterprises has led to the descent gradient increase in the equilibrium pollutant production of enterprises $\left(\omega g(1-R) /\left(v_{i}+C_{i} R^{2}\right)\right)$. It shows that when the cost of emissions of enterprises is reduced, the pollution control effect of the government's ecological civilization and environmental performance assessment is further strengthened.

Similarly, reduction in production and operation costs $v_{i}$ of enterprises has led to the descent gradient increase in the equilibrium pollutant production of enterprises $\left(\omega g(1-R) /\left(v_{i}+C_{i} R^{2}\right)\right)$. It shows that when the production and operation costs of enterprises are reduced, the pollution control effect of the government's ecological civilization and environmental performance assessment will be further strengthened.

(5) Increasing the penalties $\omega$ for the environmental illegal activities of polluting enterprises can improve the effect of environmental pollutant control. By partial guidance of the equilibrium pollutant production $e_{i}^{*}(s)$ on the penalties $\omega$, we can obtain $\left(\partial e_{i}^{*}(s) / \partial \omega\right)=\left(-\alpha(s) g(1-R) /\left(v_{i}+C_{i} R^{2}\right)\right)$. Since $0<R<1$ and $\alpha(s), g, v_{i}$, and $C_{i}$ are all greater than zero, then $\left(-\alpha(s) g(1-R) /\left(v_{i}+C_{i} R^{2}\right)\right)<0$ is always established. So, we see that the enterprises' equilibrium pollutant production $e_{i}^{*}(s)$ is negatively related to the punishment $\omega$ from the government. That is to say, the punishment for the discharge pollutant without permission, beyond pollution limits, and other environmental illegal activities of enterprises will be continuously increased. When the number of fines for the discharge pollutant without permission, beyond pollution limits, and other environmental illegal activities of enterprises is greater than the cost of environmental pollution control, it may reduce the environmental illegal activities of enterprises.

(6) The superior government will increase the rewards and punishments $\vartheta$ for the local government's ecological civilization and environmental protection achievements, which can improve the level of its environmental governance efforts. By partial guidance of the government's equilibrium environmental governance efforts $\mu^{*}(s)$ on the rewards and punishments $\vartheta$, we can obtain $\left(\partial \mu^{*}(s) / \partial \vartheta\right)=(g \alpha$ $\left.(s) / 2 C_{g} \beta^{2}\right)$. Since $\alpha(s), g, C_{g}$, and $\beta$ are all greater than zero, then $\left(g \alpha(s) / 2 C_{g} \beta^{2}\right)>0$ is always established. So, we see that the government's equilibrium environmental governance efforts $\mu^{*}(s)$ is positively related to the rewards and punishments $\vartheta$. Therefore, the superior government should increase the reward and punishment of environmental performance assessment; when the environmental performance assessment really affects the government's interests, it will have more power to invest in environmental pollution control.

(7) The government's lower environmental governance costs $C_{g}$ can raise the level of its equilibrium environmental governance efforts $\mu^{*}(s)$. The government's environmental pollution control cost $C_{g}$ is reduced, making the rising gradient $g 9 / 2 C_{g} \beta^{2}$ of the government's equilibrium governance effort $\mu^{*}(s)$ related to the importance of ecological civilization and environmental performance assessment $\alpha(s)$ increase. It shows that, with the reduction in government environmental governance costs, the government's equilibrium pollution control efforts will further increase.

\section{Numerical Examples}

The results presented thus far, while analytically compelling, may further benefit from practical grounding in a real-world example. This section thus assesses the results of the game theoretic models against a realistic backdrop of the 
assessment mechanism of ecological civilization construction deployed at Hubei Province, China. A numerical illustration serves to illustrate (i) how dynamic state variables shape expectations and variance in the stock of pollutants and (ii) how related and key parameter values affect equilibrium strategies of both sides of the game.

4.1. Hubei Province, China. Hubei Province is in the south of China and in the middle reaches of the Yangtze River. It is between $29^{\circ} 05^{\prime}$ and $33^{\circ} 20^{\prime}$ north latitude and $108^{\circ} 21^{\prime}$ to $116^{\circ} 07^{\prime}$ east longitude and boasts advantageous geographical location. The Yangtze River runs from west to east and traverses the province's 1062 kilometers. The Yangtze River and its largest tributary, the Han River, run the river, the water network is vertical and horizontal, and the lake is densely covered. Hubei Province is also known as the "Thousand Lakes Province."

After Hubei province included ecological civilization construction in the performance review, the local government has implemented stringent environmental management systems. Since 2016, the Hubei provincial government has outlawed 1103 piers, recovered coastline by $143 \mathrm{~km}$ and cleared 744 solid waste storage points. Therefore, the proportion of category I III water quality in 27 primary tributaries of Yangtze River has been rising year by year. Moreover, the local government has enhanced lake governance by removing $1.2754 \mathrm{mn}$ acres of fences and breeding cages, outlawing $274.5 \mathrm{k}$ acres land of fertilizer (manure) breeding as well as pearl farming. Hubei's government has also completed renewal of sewage management plant in 88 towns. It also spent RMB $\$ 30$ bn to deploy sewage management facilities in all of its towns and relocated 12784 livestock and poultry farms in the breeding forbidden zone. The funding was raised via local government bonds. From January-October 2018, water quality of Tongshun River's tributaries was improved from category $\mathrm{V}$ (poor quality) to category IV. The water quality of Shending River, Ju River, and Yiai River has experienced continual improvement (https://baijiahao.baidu.com/s? $\mathrm{id}=1632754276131852877$ ).

The following model is combined with the previous model to assign values to external variables and give numerical simulations (numerical simulation is through numerical calculation and image display method to achieve the purpose of research on the control of environmental pollution behaviors of enterprises). First, assume that there are four enterprises in total, that is, $n=4$ (the number of enterprises can be set to any positive integer and the adjustment of parameters will have a certain effect on the results of numerical simulation but does not affect the overall trend). The enterprise obtains certain benefits through production and operation activities. For the convenience of calculation, suppose the benefit coefficients is $a_{i}=20$; at the same time, it costs a certain amount, and the initial cost coefficients are $v_{i}=0.1$. For the enterprises, they need to pay a certain sewage charge to the government for each the unit of pollutants discharge, if the initial unit of sewage charges is $G=0.4$. The enterprise conforms to the hypothesis of "rational economic man." In order to pursue the maximum profit, it will risk the selection of environmental violations such as discharge pollutant without permission, beyond pollution limits, and other illegal activities and assume that the income per unit of excess pollutant discharge will bring $k=10$ to the enterprise. The government imposes a certain fine on the enterprise's discharge pollutant without permission, beyond pollution limits, and other illegal activities if the penalty for exceeding the pollutants per unit is $\omega=2$. The government's supervision is influenced by the importance of ecological civilization and environmental performance assessment $\alpha(s)$; the value range of $\alpha(s)$ is $(0,1)$, and the value of $\alpha(s)$ is closer to 1 , explaining that the ecological civilization environmental performance assessment is more important and the initial $\alpha(s)$ is set to 0.8 . The government's environmental performance level $g$ is in the range of $0<g<1$, and the value of $g$ is closer to 1 , explaining that the government's environmental performance is higher and the initial $g$ is set to 0.7 . Therefore, under the supervision of the government, the enterprises will carry out a certain degree of technical input to improve the pollution purification rate. The value of the pollution purification rate $R$ in the production process caused by the change in technology is $0<R<1$, and the initial $R$ is set to 0.2 . The cost coefficient of environmental management of enterprises is $C_{i}=0.3$. When the ecological environment is polluted, the government will curb environmental pollution, and suppose the amount of pollution $\beta=0.3$ is being eliminated by the government on curb environmental pollution. The cost coefficient of government's curb environmental pollution is $C_{g}=0.04$. The superior government will give certain rewards according to the efforts of the local government's curb environmental pollution and the level of environmental performance, and the initial coefficient of reward is $\vartheta=0.01$. The damage to the local people caused by environmental pollution $\zeta=0.1$ and the harm to the enterprise $b=0.05$, the discount rate of the enterprise (government) $\rho=0.005$, and the self-purification rate of the ecological environment $m=0.1$. The maximum level of pollution $P_{\max }=1000$.

4.2. Analysis of Pollutant Stock and Sensitivity Analysis of Equilibrium Feedback. Substituting the above-set parameter values into the feedback Nash equilibrium solution of the differential game, we can conclude that $e_{i}^{*}(s)=225.54$ and $\mu^{*}(s)=80.14$. Substituting the value of the feedback Nash equilibrium solution into the environmental quality dynamic equation (1), the following equation can be obtained: $E(s)=797.869-597.869 e^{-0.1 s}$. The dynamic evolution of environmental quality is shown in Figure 1. From Figure 1, we can see that as time $s$ goes on, the environmental quality $E(s)$ will continue to improve and eventually stabilize. This can also better explain the rationality and high practical value of the model. At the beginning of time, the environmental quality has improved rapidly with the external intervention for a period of time, but the longer the time, the external the environmental governance and scientific and technological means to regulate the environmental behavior of enterprises, which makes the amount of pollution and 


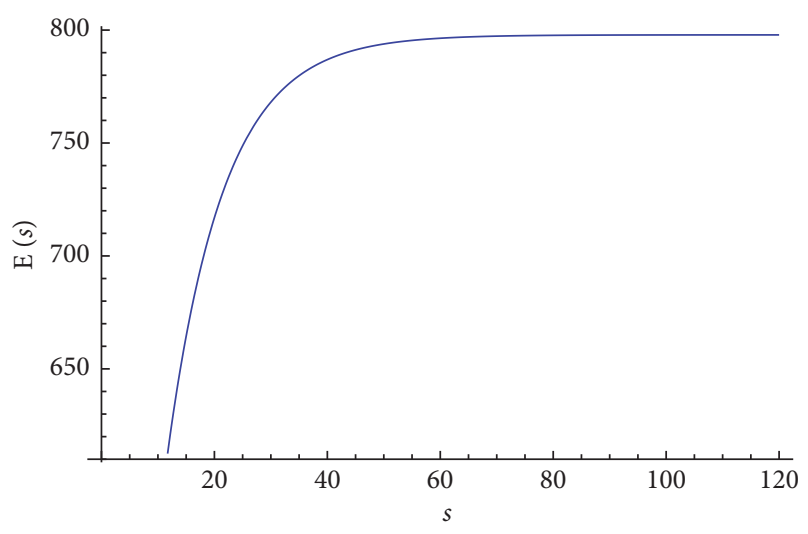

Figure 1: The dynamic evolution of environmental quality $E(s)$.

environmental self-absorption reach a balance so that the environmental quality will evolve to a stable state.

In Figure 2, based on the selected parameter values in Section 4.1, the environmental performance assessment $\alpha(s)$ is used to locate the independent variables, the blue imaginary curve $e(s 1)$ is obtained using Mathematica 9.0 software, and it indicates the evolution trend of the pollutant output of the enterprise under the condition that the importance level of the ecological civilization environmental performance assessment $\alpha(s)$ changes; in the same way, the environmental performance assessment $\alpha(s)$ and unit sewage charges $G$ are used to locate the independent variables, and the red solid curve $e(s 2)$ is obtained using Mathematica 9.0 software; it indicates the evolution trend of pollutant production of enterprises under the dual role of unit sewage charges and the importance of ecological civilization and environmental performance assessment $\alpha(s)$. The production level of enterprise pollutants $e_{i}(s)$ is negatively related to the importance level of ecological civilization and environmental performance assessment. With the increasing importance of ecological civilization and environmental performance assessment, the output of enterprise pollutants has been declining. However, if the means of increasing the unit sewage charges is taken at the same time, the production of pollutants will be reduced at a faster rate, as shown by the curve $e(s 2)$.

In Figure 3, based on the selected parameter values in Section 4.1, the environmental performance assessment $\alpha(s)$ is used to locate the independent variables, and the blue imaginary curve $\mu(s 1)$ is obtained using Mathematica 9.0 software; it represents the evolutionary trend of the government's level of environmental governance efforts as a result of change in the importance level of ecological civilization and environmental performance assessment $\alpha(s)$; in the same way, the environmental performance assessment $\alpha(s)$ and the government's environmental performance level $g$ are used to locate the independent variables, and the red solid curve is obtained using Mathematica 9.0 software, and it represents the evolutionary trend of the government's environmental governance efforts under the dual role of the importance of ecological civilization and environmental performance assessment $\alpha(s)$ and the government's environmental performance level $g$. It can be seen that the level

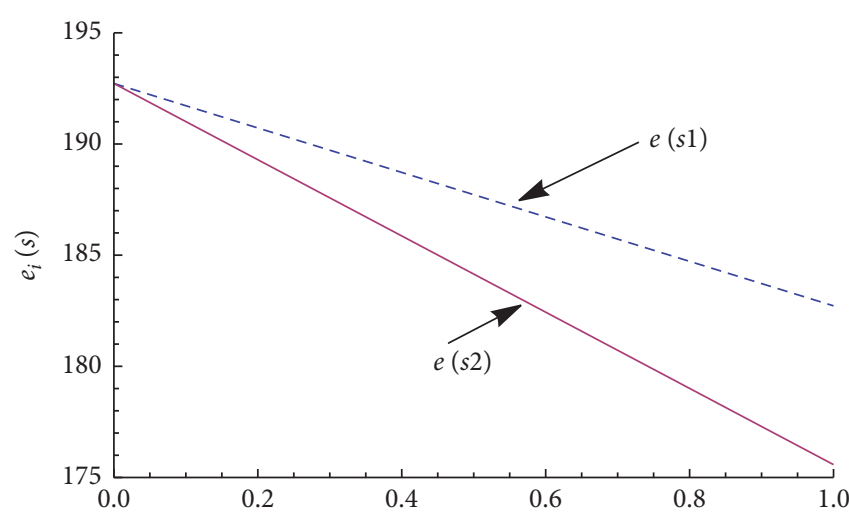

FIgURE 2: Evolution trend of enterprise pollutant production $e_{i}(s)$ under different regulations.

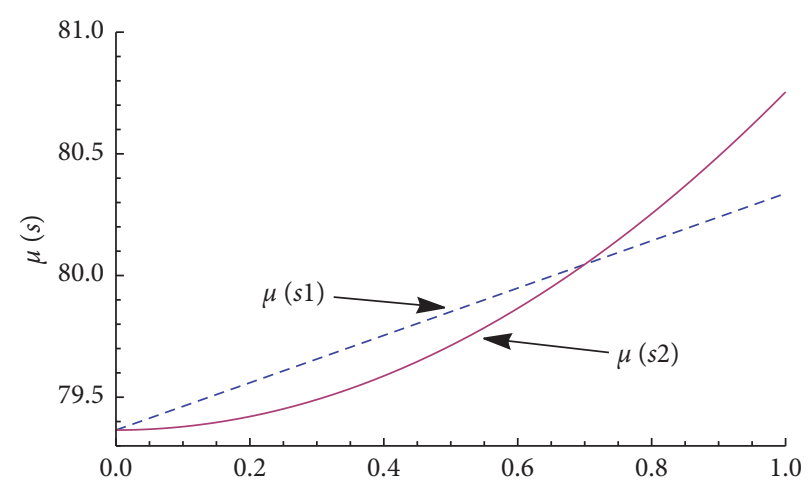

FIgURE 3: The evolutionary trend of government environmental governance efforts $\mu(s)$ under the influencing factors.

of government's environmental governance efforts $\mu(s)$ is positively related to the importance of ecological and environmental protection performance assessment $\alpha(s)$. By comparing the curve $\mu(s 1)$ and the curve $\mu(s 2)$, we can find that the slope of the curve $\mu(s 2)$ increases the slope of the curve larger than the slope of the curve $\mu(s 1)$ with the double effect of the importance of ecological and environmental protection performance assessment and the government's environmental performance level, indicating the assessment of ecological civilization and environmental performance. The greater the effect, the greater the intensity of punishment, the better the performance of government environmental governance efforts $\mu(s)$.

\section{Policy Implications}

This study develops the differential game method to construct a game model of environmental pollution control between enterprises and local governments accounting for uncertain dynamics in pollution stocks and environmental factors and obtain a set of feedback Nash equilibrium solutions. By the analysis of the equilibrium solution and the numerical simulation, governmental ecological civilization and environmental protection efforts could reduce enterprises' discharged pollution. The government's efforts to curb environmental pollution could also be improved. 
Therefore, we must fully recognize that ecological civilization environmental assessment plays a role in guiding, stimulating, and restraining environmental protection. By the analysis of the equilibrium solution, with validation via a numerical simulation based on the Hubei case, this study returns several insights.

\subsection{Improve the Weight of Ecological Civilization Indicators in} the Government Performance Appraisal $\alpha(s)$ and Formulate Reasonable Local Government Ecological Civilization Environmental Protection Performance Appraisal and Reward and Punishment System $\vartheta$. As mentioned above, we can assume that the equilibrium pollution production of enterprises $e_{i}^{*}(s)$ is negatively correlated with the importance of ecological civilized environmental performance assessment $\alpha(s)$; the government's equilibrium of environmental governance efforts $\mu^{*}(s)$ is positively related to the importance of ecological civilization and environmental performance assessment $\alpha(s)$. Therefore, it is necessary to enhance the importance of ecological civilization indicators $\alpha(s)$ in the government's performance evaluation and effectively revoke the concept that GDP is the only standard for local development and government work performance.

Establish a reasonable ecological civilization and environmental performance evaluation mechanism to ensure the fairness of the assessment. On the one hand, it is necessary to conduct regular environmental performance assessments, such as monthly reports, semiannual assessments, and annual assessment mechanisms. On the other hand, environmental performance assessment can be used as a management tool. This can not only stimulate active attitudes and work behavior of relevant personnel but also may have a drumming effect on their negative work attitudes and behavior [24]. Therefore, we must fully consider the fairness of performance appraisal. We can refer to the three-dimensional model of performance appraisal fairness proposed by Levy and Williams [25]. We should design the environmental performance appraisal system from the distribution fairness dimension, program fairness dimension, and interactive fairness dimension of assessment.

Construct a reasonable ecological civilization and environmental protection performance reward and punishment mechanism. Local governments' interests have different manifestations according to different classification criteria. From the content point of view, the government interests mainly include political interests and economic interests. From the perspective of hierarchy, it includes three levels: interests of individual officials, interests of local governments and departments, and the overall interests of government organizations. The personal interests of officials lie in the fact that each official as an economic person and a social person has his/her own value orientations. Local government and departmental interests refer to them as a strong and relatively independent interest subjects, pursuing different levels of institutional interests, namely, specific sectoral interests. Finally, the overall interests of the organization include the rapid growth of government public expenditure, the expansion of institutions, and the conscious inertia of institutions [26]. Therefore, the construction of ecological civilization and environmental protection performance reward and punishment mechanism need to start from the above aspects: (a) link between the political interests and economic interests of local governments, (b) and link between personal interests of officials, local government interests, and (c) departmental interests and the overall interests of government organizations.

\subsection{Accelerate the Establishment of Reward and Punishment} Mechanism for Corporate Emissions and Establish Reasonable Standards for Collecting Sewage Charges. Formulate reasonable reward and punishment mechanism for the enterprise environmental behavior. Firstly, we recommend increase in penalties for the enterprises making pollution based on the environmental regulations. We advise that the government adopts a variety of punishments such as stepped fine system, production suspension, enforced closure or rectification of the factories, and media exposure. These measures could help completely reverse the situations including severe enterprises pollution, low illegal costs, and high law-abiding costs. Secondly, we believe that the government should reward enterprises that actively implement emission reduction technology innovation and clean production. The reward could include financial subsidies, low-interest loans, tax benefits, government preferential procurement and other policy incentives, and positive media exposure. It is necessary to increase support for the enterprises that adopt eco-friendly innovative technologies for emission reduction. This is because implementation of cutting-edge emission reduction technology is a high-risk and large investment. The long-term investment is less likely to translate into a considerable benefit in the near term. The favorable supportive measures could reduce operational risks caused by the emission reduction technology innovation to the enterprise to a certain extent. As mentioned above, with a new carrot-and-stick package of measures, the government may establish positive incentives and reverse restraint policies, namely, forming climate law enforcement atmosphere with clear rewards and punishments. By creating a law-abiding environment, we believe that companies will eventually tend to work with the interests of the government to promote the realization of legal emissions.

Formulate reasonable standard for the collection of sewage charges. At present, collection standards for sewage charges in China are generally low. The sewage charges paid by enterprises are far less than the cost of pollution control. Therefore, collection of sewage charges has not achieved policy effect. China's Regulations on the Administration of the Collection and Use of Sewage Charges has not been revised since implementation on July 1, 2003. With the continual deterioration of environmental problems, current standards for sewage discharge are far from addressing the environmental pollutions in China. Therefore, the government needs to revise the current regulations on collection of sewage charges and tighten the collection standards for sewage charges to effectively curb the number of pollutants 
generated by enterprises. Central or local governments should incur higher sewage fees at a reasonable level and increase the sewage pollution management cost. The move may help mitigate the damaging effects indirectly caused by the environmental pollutions.

Enhance the ability of independent innovation and reduce enterprise cost of production and emission cut. In order to thoroughly curb environmental pollution, we must use technological progress and innovation. Innovation is a key for an enterprise's sustainable growth and the firm's competitiveness in the market. Innovation would reduce the cost of production and operation, improve the quality and quantity of products, enable enterprises to obtain the advantage in the cost, enhance the enterprise's competitiveness, and promote the enterprise's product lines. Moreover, technological innovation, clean production technologies, and process transformation can not only greatly improve the utilization efficiency of resources but also reduce water pollution. Enterprises can also develop dirt removal and filtration devices through technological innovation to reduce abatement cost. They can even turn waste into waste recycling, creating more revenue. Thus, enterprises must change their way of thinking, establish the awareness of independent innovation, and recognize the importance and urgency of independent innovation. Also, they must increase research investment by implementing more funding and recruiting more talent; for instance, by introducing highquality talents from higher education institutions, enterprises can rebuild technological innovation teams. Purchasing environmental treatment devices domestically and internationally could help improve the research quality. Finally, enterprises should transform itself by accelerating technological innovation.

Improve the government's environmental protection work capacity and reduce pollution control costs. As mentioned above, the government's environmental governance costs reduction can improve equilibrium of environmental governance efforts. The government's environmental governance costs mainly include the engineering costs and management costs of pollution control. The following measures are needed to reduce the cost of environmental governance; for instance, actively carry out scientific and technological research, employ Internet of Things (IoT) technologies to build an integrated network of environmental pollution monitoring and reduce supervision costs, and create good government websites to engage in public participation.

\section{Conclusions and Limitations}

This study develops the differential game method to construct a game model of environmental pollution control between enterprises and local governments. However, most scholars adopt common static games, dynamic games, and evolutionary games. They do not take into account changes in pollution volume in the environment and the influence of one of the game's strategies on the other side of the game as the pollutants would change. The environmental pollution control process is a dynamic process. Due to the information asymmetry and the subject's limited rational participation behavior, it is difficult to achieve specific equilibrium between the participating subjects after a decision-making process. The players need to interact with each other dynamically to achieve the final equilibrium. The differential game just makes up for the shortcomings of the traditional game method. Differential game is extending the game theory to continuous time. Game participants can change their strategies in an infinitesimal time period. It fully takes into account the environmental damage and the impact of the whole game by the cumulative process of enterprises' emissions. The essence of the game is that the players make decisions in a time interval and consider a problem of intertemporal optimization. In differential games, each player has his own payment function, which depends on a deterministic dynamic system, that is, the system on which the state variable changes. In a static game, the choice of the player is called strategy, while in a differential game, the strategy is called control. In the framework of the differential game, control depends on time and system state changes, and the obtained feedback Nash equilibrium solution is Markov perfect.

Although the aim of this paper is to primarily guide future research, it may also help to get practitioners involved in the realm of environmental management and environmental performance amid ecological civilization. More theoretical and empirical researches in this area would lead to policy improvements. Specifically, research shows the following: (1) improve the weight of ecological civilization indicators in the government performance appraisal $\alpha(s)$ and formulate reasonable local government ecological civilization environmental protection performance appraisal, and reward and punishment system 9 ; (2) accelerate the establishment of reward and punishment mechanism for corporate emissions and establish reasonable standards for collecting sewage charges.

The results of the research would participate in government initiatives to address environmental issues and carry out incorporate extraorganizational policies. And the research could also highlight the potential problems after the researchers assess the government's performance in ecological progress. To sum up, polluters and local governments should recognize the benefits of environmental management and appreciate the resulting long-term performance improvements [16].

\section{Data Availability}

The numerical simulations data used to support the findings of this study were supplied by Liuwei Zhao under license and so cannot be made freely available. Requests for access to these data should be made to Liuwei Zhao (e-mail address: 136901672@qq.com).

\section{Conflicts of Interest}

The authors declare that there are no conflicts of interest. 


\section{Acknowledgments}

This work was supported by the National Nature Science Foundation of China (nos. 71974081 and 92046022) and Philosophy \& Social Science Fund for University of Jiangsu (no. 2019SJA1051).

\section{References}

[1] H.-L. Li, X.-H. Zhu, J.-Y. Chen, and F.-T. Jiang, "Environmental regulations, environmental governance efficiency and the green transformation of China's iron and steel enterprises," Ecological Economics, vol. 165, Article ID 106397, 2019.

[2] K. Tevapitak and A. H. J. Helmsing, "The interaction between local governments and stakeholders in environmental management: the case of water pollution by SMEs in Thailand," Journal of Environmental Management, vol. 247, pp. 840-848, 2019.

[3] Y. Du, Z. Li, J. Du, N. Li, and B. Yan, "Public environmental appeal and innovation of heavy-polluting enterprises," Journal of Cleaner Production, vol. 222, pp. 1009-1022, 2019.

[4] P. Benhong, L. B. Yue, E. Ehsan, and W. Guo, "Dynamic evolution of ecological carrying capacity based on the ecological footprint theory: a case study of Jiangsu Province," Ecological Indicators, vol. 99, pp. 19-26, 2019.

[5] Y. Bian, K. Song, and J. Bai, "Market segmentation, resource misallocation and environmental pollution," Journal of Cleaner Production, vol. 228, pp. 376-387, 2019.

[6] G. Liu, Z. Yang, B. Chen, Y. Zhang, M. Su, and S. Ulgiati, "Prevention and control policy analysis for energy-related regional pollution management in China," Applied Energy, vol. 166, pp. 292-300, 2016.

[7] K. Jiang, D. You, R. Merrill, and Z. Li, "Implementation of a multi-agent environmental regulation strategy under Chinese fiscal decentralization: an evolutionary game theoretical approach," Journal of Cleaner Production, vol. 214, pp. 902-915, 2019.

[8] Z. Sun and W. Zhang, "Do government regulations prevent greenwashing? an evolutionary game analysis of heterogeneous enterprises," Journal of Cleaner Production, vol. 231, pp. 1489-1502, 2019.

[9] K. Jiang, D. You, Z. Li, and S. Shi, "A differential game approach to dynamic optimal control strategies for watershed pollution across regional boundaries under eco-compensation criterion," Ecological Indicators, vol. 105, pp. 229-241, 2019.

[10] X. Yunan, L. Weixin, Y. Yujie, and W. Hui, "Evolutionary game for the stakeholders in livestock pollution control based on circular economy," Journal of Cleaner Production, vol. 282, no. 1, Article ID 125403, 2021.

[11] J. Jiao, J. Chen, L. Li, and F. Li, "A study of local governments' and enterprises' actions in the carbon emission mechanism of subsidy or punishment based on the evolutionary game," Chinese Journal of Management Science, vol. 25, no. 10, pp. 140-150, 2017.

[12] F. Pan, B. Xi, and L. Wang, "Analysis on environmental regulation strategy of local government based on evolutionary game theory," Systems Engineering-Theory \& Practice, vol. 35, no. 6, pp. 1393-1404, 2015.

[13] W. Chen and Z.-H. Hu, "Using evolutionary game theory to study governments and manufacturers' behavioral strategies under various carbon taxes and subsidies," Journal of Cleaner Production, vol. 201, pp. 123-141, 2018.
[14] F.-Y. Lu, "Evolutionary game analysis on environmental pollution problem," Systems Engineering-Theory \& Practice, vol. 27, no. 9, pp. 148-152, 2007.

[15] P. Benhong, W. Yuanyuan, E. Ehsan, and W. Guo, "Behavioral game and simulation analysis of extended producer responsibility system's implementation under environmental regulations," Environmental Science and Pollution Research, vol. 26, no. 17, pp. 17644-17654, 2019.

[16] P. Benhong, W. Yuanyuan, Z. Sardar, W. Guo, and E. Ehsan, "Platform ecological circle for cold chain logistics enterprises: the value co-creation analysis," Industrial Management \& Data Systems, vol. 120, no. 4, pp. 675-691, 2020.

[17] D. W. K. Yeung and L. A. Petrosyan, "A cooperative stochastic differential game of transboundary industrial pollution," Automatica, vol. 44, no. 6, pp. 1532-1544, 2008.

[18] G. Kossioris, M. Plexousakis, A. Xepapadeas, A. de Zeeuw, and K.-G. Mäler, "Feedback Nash equilibria for non-linear differential games in pollution control," Journal of Economic Dynamics and Control, vol. 32, no. 4, pp. 1312-1331, 2008.

[19] A. Yanase, "Global environment and dynamic games of environmental policy in an international duopoly," Journal of Economics, vol. 97, no. 2, pp. 121-140, 2009.

[20] S. Jorense and G. Zaccour, "Time consistent side payments in a dynamic game of downstream pollution," Journal of Economic Dynamics and Control, vol. 25, no. 12, pp. 1973-1987, 2001.

[21] S. Xu and C. Han, "Study on bain ecological compensation mechanism based on differential game theory," Chinese Journal of Management Science, vol. 27, no. 8, pp. 199-206, 2019.

[22] L. Musu and M. Lines, "Endogenous growth and environmental preservation," in Environmental Economics: Proceedings of European Economic Associations at Oxford, 1993, G. Boero and A. Silberston, Eds., St Martins Press, London, UK, 1995.

[23] L. W. Zhao and C. O. A. Otoo, "Stability and complexity of a novel three-dimensional environmental quality dynamic evolution system," Complexity, vol. 2019, Article ID 3941920, , 2019.

[24] Y. J. Zhang, A Dissertation Submitted in Partial Fulfillment of the Requirements for the Degree of Doctor of Philosophy in Management, Huazhong University of Science and Technology, Wuhan, China, 2012.

[25] P. E. Levy and J. R. Williams, "The social context of performance appraisal: a review and framework for the future," Journal of Management, vol. 30, no. 6, pp. 881-905, 2004.

[26] X. Y. Wu and A. P. Pu, "On the government interest of public policies," Journal of Yanbian Party School, vol. 24, no. 2, pp. 37-40, 2009. 